Conclusion Postnatally acquired CMV infection among preterm infants is not related with SNHL during the first and second year of life.

\section{GESTATIONAL AGE AND PREGNANCY DISORDERS AS RISK FACTORS FOR CEREBRAL PALSY}

doi:10.1136/archdischild-2012-302724.1259

${ }^{1} \mathrm{H}$ Trønnes, ${ }^{1} \mathrm{RT}$ Lie, ${ }^{2} \mathrm{~T}$ Markestad, 1,2D Moster. ${ }^{1}$ Department of Public Health and Primary Health Care; ${ }^{2}$ Department of Clinical Medicine, University of Bergen, Bergen, Norway

Background Both pregnancy disorders and low gestational age (GA) are associated with an elevated risk of cerebral palsy (CP). As many pregnancy disorders are associated with preterm birth, it is unclear whether the increased risk of $\mathrm{CP}$ in preterm children can be attributed to the pregnancy disorder or the low GA.

Aim To disentangle the risk of CP according to GA and pregnancy disorders in children born preterm.

Method Norwegian, national cohort study with linkage of the Medical Birth Registry of Norway to the Statistics Norway and the National Insurance Scheme. All births from 1967 to 2001 were followed through 2005, and 1,499,705 individuals were included in the cohort.

Results Placental abruption, chorioamnionitis, placenta previa, multiple birth, prolonged rupture of membranes, cervical conisation, unspecified bleeding and pre-eclampsia were associated with an increased risk of CP. The risk of CP increased with decreasing GA (23-27 wks RR 83.3 [95\% CI, 69.8-99.4], 28-30 wks RR 49.5 [95\% CI, 43.2-56.6], 31-33 wks RR 17.4 [95\% CI, 15.3-19.7], 34-36 wks RR 3.3 [95\% CI, 2.9-3.8]). The association between GA and CP was not substantially weakened after adjustment for pregnancy disorders.

Conclusion Although several pregnancy disorders were associated with an increased risk of CP, low GA appeared to be a more important risk factor for $\mathrm{CP}$ in preterm children.

\section{NEUROSENSORY OUTCOMES AND HEALTH CARE NEEDS IN SCHOOL-AGE CHILDREN BORN AT < 26 WEEKS' GESTATION AFTER ACTIVE PERINATAL CARE}

doi:10.1136/archdischild-2012-302724.1260

${ }^{1} \mathrm{~A}$ Faroogi, ${ }^{1} \mathrm{~A}$ Hautaniemi, ${ }^{2 B}$ Hägglöf, ${ }^{3} \mathrm{~F}$ Serenius. 'Dept of Pediatrics, Inst of Clinical Sciences, Umeå University; ${ }^{2}$ Child and Adolescent Psychiatry, Inst of Clinical Sciences, Umeå University, Umeå; ${ }^{3}$ Women and Child Health, Uppsala University, Uppsala, Sweden

Background and Aims To examine neurosensory outcomes and special health care needs in 10 to 16 -year-old extremely preterm (EPT) children born at 2 tertiary care centers in Sweden adhering to a policy of universal resuscitation of all infants born alive.

Design and methods The outcomes of 122 surviving EPT children were compared to a matched control of children born at term. Neurosensory impairments (NSI) were assessed by review of pediatric case records, intelligence by WISC-III, and functional limitations and special health care needs by validated parental interviews (QUICCC).

Results Of 213 consecutive EPT live births, 140 (66\%) survived to discharge home and 6 infants died in the first year of life. Of survivors, 122 children (91\%) were recruited for the study. Table1 shows rates of disabilities. EPT children had significantly higher rates of functional limitations and special health care needs than controls but the vast majority was free from severe disability that curtail them from activities of daily life.
Abstract 1260 Table 1 Rates of Disability

\begin{tabular}{lll}
\hline Disabilty & EPT (N = 121) & Control (N= 100) \\
\hline None & $45.4 \%(55)$ & $90 \% * *$ \\
Mild & $28.9 \%(35)$ & $7 \%^{* *}$ \\
Moderate & $19.8 \%(24)$ & $3 \%^{* *}$ \\
Severe & $6.6 \%(8)$ & $0 \% *$
\end{tabular}

Severe Disability: Severe CP (inability to walk), Blindness (visual acuity $<20 / 200$ in better eye), or $10<-3$ SD; Moderate disability, moderate CP (considerable difficulty in walking with or without appliances), deafness requiring bilateral aids or worse or $10-3 S D$ to $<-2 S D$; Mild disability; mild $\mathrm{CP}$ (walking with minimal limitation), or an $\mathrm{IO}-2 \mathrm{SD}$ to $<-1 \mathrm{SD}$; ${ }^{*} \mathrm{P}<0.05 ;{ }^{*} \mathrm{P}<0.005$

Conclusions Disability rates and special health care needs remain high in EPT children, but have not increased since 1990s despite the marked increase in their survival.

\section{NEURODEVELOPMENTAL OUTCOME IN EXTREMELY PREMATURE INFANTS BORN IN SWITZERLAND BETWEEN 2000-2008, PRELIMINARY DATA OF THE SWISS NEONATAL NETWORK}

doi:10.1136/archdischild-2012-302724.1261

'LJ Schlapbach, ${ }^{2} \mathrm{M}$ Adams, ${ }^{3} \mathrm{M}$ Aebischer, ${ }^{4} \mathrm{~B}$ Latal, ${ }^{5} \mathrm{~S}$ Grunt, ${ }^{6} \mathrm{C}$ Borradori-Tolsa, ${ }^{7} \mathrm{M}$ Bickle-Graz, ${ }^{2} \mathrm{HU}$ Bucher, ${ }^{2,4} \mathrm{G}$ Natalucci, for the Swiss Neonatal Network \& FollowUp Group. . Pediatric Critical Care Reasearch Group, Mater Children's Hospital, Brisbane, Australia, Brisbane, OLD, Australia; 'Division of Neonatology, Zurich University Hospital, Zurich; ${ }^{3}$ Pediatric Intensive Care Unit, Department of Pediatrics, Bern University Children's Hospital, Bern; ${ }^{4}$ Child Development Center, Zurich University Children's Hospital, Zurich; ${ }^{5}$ Department of Neuropaediatrics, Bern University Children's Hospital, Bern; ${ }^{6}$ Division of Development and Growth, Geneva University Children's Hospital, Geneva; 'Department of Child Development, CHUV Lausanne, Lausanne, Switzerland

Introduction So far, national outcome data on extremely premature infants in Switzerland were not available, and discussions on the care of these patients were based on earlier studies from other countries. This national study assessed neurodevelopment in Swiss infants born between 2000 and 2008 at $240 / 7$ to $276 / 7$ weeks gestational age.

Methods Neurodevelopment was assessed at 2 years using the BSID II. Moderate neurodevelopmental disability (ND) was defined as a mental (MDI) or psychomotor (PDI) development index of $55-70$, or mild cerebral palsy (GMFCS level 2). Severe ND was defined as a MDI or PDI $<55$, cerebral palsy (GMFCS level $\geq 3$ ), deafness or blindness. Multivariate logistic regression was performed.

Results Among the 1147 extremely preterms born during the study period 303 (26\%) died. Follow-up information was available in $684(81 \%)$ survivors. 440 (64\%) showed normal development, 166 (24\%) moderate ND, and 78 (12\%) severe ND. Severe ND was significantly $(p<0.05)$ associated with earlier year of birth, major intracerebral lesions, bronchopulmonary dysplasia, grade 3 retinopathy of prematurity, and lower socioeconomic status. In contrast, birth weight, gestational age and sex showed only trendwise associations with severe ND

Conclusion Based on these preliminary analyses, we now are ready to establish representative Swiss national data on the outcome of extremely premature infants. These will offer guidance to obstetricians, neonatologists, neurologists and parents based on Swiss data.

\section{PREVALENCE OF HEARING IMPAIRMENTS AT AGE FOUR YEARS IN EXTREMELY PRETERM INFANTS}

doi:10.1136/archdischild-2012-302724.1262

'A Grahn, 'S Horsch, 'B Skiöld, 'M Blennow, ${ }^{2}$ Uhlén, 'B Hallberg. 'Neonatology; ${ }^{2}$ Audiology, Karolinska Institutet and University Hospital, Stockholm, Sweden 